\title{
Identification of novel oestrogen receptor target genes in human ZR75-1 breast cancer cells by expression profiling
}

\section{Soulez and M G Parker}

\author{
Molecular Endocrinology Laboratory, Imperial Cancer Research Fund, 44 Lincoln's Inn Fields, \\ London WC2A 3PX, UK \\ (Requests for offprints should be addressed to M G Parker, Molecular Endocrinology Laboratory, \\ Institute of Reproductive and Developmental Biology, Faculty of Medicine, Imperial College, \\ Hammersmith Campus, Du Cane Road, London W12 ONN, UK; Email: m.parker@ic.ac.uk)
}

\begin{abstract}
Oligonucleotide microarrays were used to analyse gene expression profiles in human ZR75-1 breast cancer cells in the presence of $17 \beta$-oestradiol and oestrogen antagonists. Differential gene expression of a number of genes was confirmed by quantitative RNA analysis. In addition to known oestrogenresponsive genes, an appreciable number of novel targets were identified, including growth factors and components of the cell cycle, adhesion molecules, enzymes, signalling molecules and transcription factors. The most pronounced oestrogen-sensitive gene was that for the cytochrome P450-IIB enzyme, involved in metabolising steroids and xenobiotics, which was increased 100 -fold over a $24 \mathrm{~h}$ period. It is a direct target gene for oestrogens, because its expression was increased in the presence of
\end{abstract}

cyclohexamide. In contrast, expression of cytochrome P450-IIB was not detected in human MCF7 breast cancer cells. Expressions of the cationic amino acid transporter E16, gap junction protein and insulin-like growth factor binding protein 4 were also markedly increased by oestrogens, but the kinetics of induction varied according to the target gene. With the exception of the cationic amino acid transporter E16 and the insulin-like growth factor binding protein 4 , the expression of the majority of the genes was unaffected by antioestrogen treatment. Further analysis of this set of markers will provide alternative approaches to the investigation of the mitogenicity of oestrogens in breast cancer cells.

Fournal of Molecular Endocrinology (2001) 27, 259-274

\section{INTRODUCTION}

The oestrogen receptor (ER) is an important pharmaceutical target for hormone replacement treatment in menopausal women and for endocrine adjuvant therapy for the management and, recently, the prevention of breast cancer (Jordon \& Morrow 2000). A wide repertoire of structurally distinct compounds bind to ER with differing degrees of affinity and potency. Some of these compounds, such as the natural ligand, $17 \beta$-oestradiol, act solely as receptor agonists, whereas others, such as faslodex (ICI 182,780), function as pure antagonists (Wakeling \& Bowler 1988, Howell et al. 2000). A third category, termed selective ER modulators (SERMs), are capable of acting as either agonists or antagonists, depending on the target cell type or tissue (Dhingra 1999, Jordon \& Morrow 2000). For example, tamoxifen and raloxifen function as antagonists in the breast and as agonists in bone, but differ in their effects in the endometrium, where tamoxifen is an agonist and raloxifen is an antagonist (Levenson \& Jordan 1999). Responses also vary according to the promoter and the ER isoform targeted. Thus, although both $17 \beta$ oestradiol and antioestrogens are capable of stimulating transcription from activator protein-1containing genes, this seems to be achieved primarily by means of $\mathrm{ER} \alpha$ in the presence of $17 \beta$-oestradiol, but by either ER $\alpha$ or $\operatorname{ER} \beta$ in the presence of antioestrogen (Paech et al. 1997).

To date, a relatively small number of oestrogen target genes have been identified in tissues or in cell lines. These include $p S 2$, identified by differential screening of a cDNA library from MCF7 breast cancer cells (Masiakowski et al. 1982), and cathepsin D (Westley \& May 1987). More recently, antioestrogens were shown to stimulate 
the expression of quinone reductase by using the technique of RNA differential display (Montano \& Katzenellenbogen 1997). New approaches based on DNA microarrays have been used to characterise distinctive gene expression patterns in human mammary epithelial cells and breast cancers (Perou et al. 1999). A similar approach has been used to monitor gene expression during breast cancer progression (Sgroi et al. 1999) and to characterise breast tumours (Nacht et al. 1999, Bertucci et al. 2000, Perou et al. 2000). In this way, it is possible to identify clusters of genes that show similar patterns of expression when cells are grown under different conditions.

We have used a gene expression profiling approach to identify ER target genes in human ZR75-1 breast cancer cells. Complementary RNA generated from cells grown in the presence of $17 \beta$ oestradiol, 4-hydroxytamoxifen, raloxifen or faslodex were analysed for hybridisation to Affymetrix HuGeneFL oligonucleotide microarrays and differential expression was confirmed by subsequent analysis of RNA from ZR75-1 and MCF-7 cells. In this way, we have identified known and novel oestrogen target genes.

\section{MATERIALS AND METHODS}

\section{Cell culture}

Human ZR75-1 and MCF-7 breast cancer cell lines were maintained in Dulbecco's modified Eagle's medium (DMEM) containing 10\% fetal bovine serum (Gibco Brl, Paisley, UK) and $10^{-8} \mathrm{M}$ $17 \beta$-oestradiol. For MCF7 cell culture, insulin $(10 \mu \mathrm{g} / \mathrm{ml})$ and glutamine $(4 \mathrm{mM})$ were added to the medium. The cells were plated in $175 \mathrm{~cm}^{2}$

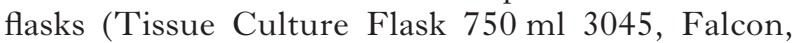
London, UK). To prepare total RNA, each cell line was cultured for 5 days in phenol-free medium containing $10 \%$ charcoal-dextran-stripped fetal bovine serum (CSS) and then maintained in phenol-free medium containing 10\% CSS and $10 \mu \mathrm{g} / \mathrm{ml}$ cycloheximide, with no hormone, $10^{-8} \mathrm{M}$ $17 \beta$-oestradiol, $10^{-7} \mathrm{M}$ 4-hydroxytamoxifen, $10^{-7} \mathrm{M}$ raloxifen or $10^{-7} \mathrm{M}$ faslodex for defined periods as specified below.

\section{Expression profiling}

Total RNA was extracted from cells using Trizol reagent (Life Technologies, Paisley, UK). Polyadenylate $(\operatorname{poly}(\mathrm{A})+)$ RNA was purified from total RNA with oligo-dT-linked Oligodetex resin (Qiagen, Crawley, UK). Two micrograms poly(A)+ RNA were converted into double-stranded cDNA (ds-cDNA) by using Superscript Choice System
(Life Technologies) with an oligo-dT primer containing a T7 RNA polymerase promoter. After second-strand synthesis, the reaction mixture was extracted with phenol-chloroform-isoamyl alcohol, and ds-cDNA was recovered by ethanol precipitation. Subsequently, complementary RNA (cRNA) was generated by in vitro transcription using a T7 Megascript Kit (Ambion AMS, Abingdon, UK) with $25 \%$ of the ds-cDNA template in the presence of a mixture of unlabelled ATP, CTP, GTP and UTP and biotin-labelled CTP and UTP (bio-11CTP and bio-16 UTP (Enz, Farmingdale, CN, USA)). Biotin-labelled cRNA was purified using an RNeasy affinity column (Qiagen), and fragmented randomly to sizes ranging from 35 to 200 bases by incubating at $94{ }^{\circ} \mathrm{C}$ for $35 \mathrm{~min}$ in $1 \times$ Affymetrix fragmentation buffer (Affymetrix, Stanford, CA, USA). The hybridisation solution contained $100 \mathrm{mM}$ 2-[N-morpholino]ethanesulfonic acid (MES), $1 \mathrm{M} \mathrm{Na}^{+}, 20 \mathrm{mM}$ EDTA and $0 \cdot 01 \%$ Tween 20 and was $0 \cdot 1 \mu \mathrm{g} / \mu \mathrm{l}$ (final concentration) of fragmented cRNA. After hybridisation at $45{ }^{\circ} \mathrm{C}$ overnight, Affymetrix HuGeneFL arrays were washed in a fluidics station with stringent buffer (100 mM MES, $0 \cdot 1 \mathrm{M} \mathrm{Na}+, 0 \cdot 01 \%$ Tween 20$)$ and non-stringent buffer $(6 \times$ SSPE, $0 \cdot 01 \%$ Tween 20$)$ and stained with streptavidin-phycoerythrin after antibody amplification. DNA chips were read at a resolution of $6 \mu \mathrm{m}$ with an Affymetrix GeneArray scanner.

\section{Data analysis}

The arrays were analysed using GeneChip 3.1 software, comparing arrays with similar signal-to-noise ratios and similar backgrounds. These arrays showed similar percentages of genes expressed. The average fluorescence intensity for each Affymetrix HuGeneFL chip was scaled to the same value so that every chip could be compared directly. For each time point, the data were analysed using the six possible comparisons (four different treatments compared two-by-two). The results were sorted using Access application and each gene selected was analysed individually in a global way (logic results for the following six comparisons: 4-hydroxytamoxifen-, raloxifen- and faslodex-treated with $17 \beta$-oestradioltreated, 4-hydroxytamoxifen-treated with raloxifenand faslodex-treated, and raloxifen-treated with faslodex-treated).

\section{RNA analysis}

Specific probes for each gene were designed, based on a BLAST search with mRNA, PCR fragment and primer sequences. Primers were selected using Primer3 (Rozen \& Skaletsky 2000). 
A $367 \mathrm{bp}$ fragment from the human transducer of ErbB2,1 (Tob) cDNA and a $291 \mathrm{bp}$ fragment from the human receptor interacting protein (RIP) 140 cDNA were amplified by PCR using pfu DNA polymerase (Stratagene, Amsterdam, The Netherlands) and the following primers: Tob-F: taccactgccacttttgctg; Tob-R: actgaggttaagggggetgt; RIP-F: cctggcagatgattcagaca; RIP-R: gcccaactcetgt gttcact. They were then cloned into pCR-Blunt II-Topo vector (Invitrogen, Paisley, UK). RNase protection probes were generated by in vitro transcription of the plasmids described above (linearized with BamHI) and of the p'TRI- $\beta$ actin-125-human plasmid (Ambion), using T7 RNA polymerase. RNase protection assays were carried out using the RPA III Kit (Ambion). Total RNA was hybridised with specific probes at $42{ }^{\circ} \mathrm{C}$ overnight, followed by digestion with RNase A/T1 . Finally, protected fragments were ethanol precipitated and separated on a 5\% polyacrylamide sequencing gel.

Northern blots and hybridisations were performed by standard techniques using $10 \mu \mathrm{g}$ total RNA and radioactive probes generated by random priming of sequence-verified PCR products amplified with elongase (Gibco Brl) and obtained with the following primers: E16-F: ctgttctgggaggtggacat; E16-R: cgtttgtcagtggagtgtgg; inositol 1,3,4 triphosphate 5/6 kinase (IP3K)-F: cagactcacccatcacctt; IP3K-R: ttgttgggtcctcagtttcc; gap junction protein (Gap)-F: ctcctcctgggtacaagctg; Gap-R: cctccaccggat caaaatta; insulin-like growth factor binding protein 4 (IGFBP4)-F: gcccaagaggactgagactg; IGFBP4-R: tggtgcaacaaccagaccta; cytochrome P450-IIB (Cyt)-F: tcctttctgaggttccgaga; Cyt-R: tggaatggaagaggaaggtg; glucose-6-phosphate dehydrogenase (G6PD)-F: atttgccaacaggatcttcg; G6PD-R: tcccacctctcattctccac; immediate early response 3 (IEX)-F: gacctcagcactttc ctcca; IEX-R: tacagcagggggaacatctc; tropomyosin 4 (TPM4)-F: cttaagacggaggccatttg; TPM4-R: gatgttt gtcctgcatggtg. The amount of TPM4 was used as an internal standard.

\section{RESULTS}

We compared gene expression profiles in human breast cancer ZR75-1 cells grown in the presence of four different ligands for the ER by exploiting GeneChip methodology. The ligands tested were the natural hormone $17 \beta$-oestradiol, the SERMs 4-hydroxytamoxifen and raloxifen, and the pure antagonist faslodex. As a first step to the identification of clusters of genes of which the expression is regulated by each ligand, we analysed patterns of expression by using Affymetrix HuGeneFL oligo- nucleotide arrays representing 5600 human genes. Cells were initially maintained in medium deprived of oestrogens for 5 days and then treated with ligand for 6 or $24 \mathrm{~h}$ in the presence of cyclohexamide to ensure that changes in gene expression were primary responses. RNA was isolated from the cells and analysed for $p S 2$ gene expression, a wellcharacterised target gene for $17 \beta$-oestradiol (Brown et al. 1984, Chalbos et al. 1993). This marker of oestrogen action was significantly increased by $17 \beta$-oestradiol relative to the oestrogen antagonists (data not shown). Poly(A)-containing RNA was isolated and used to prepare cDNA samples that were then transcribed to generate biotin-labelled cRNA to hybridise with the GeneChip HuGeneFL probe array. Expression profiles were determined using cRNA generated from cells treated with ligands for 6 or $24 \mathrm{~h}$. Hybridisation signals were first analysed using GeneChip 3.1 software and genes of interest were selected using Access software. The results were then analysed for each gene in six different comparisons at two different time-points (see Materials and Methods). This last selection allowed us to discard a large number of false-positive results.

A total of 53 genes was identified, the relative expression of which differed by more than $1 \cdot 5$-fold (Table 1; parts 1 and 2). The samples derived from cells treated with $17 \beta$-oestradiol were used as a baseline in the differential gene expression comparisons, as this highlighted the effects of the different antioestrogens. The majority of these genes were more highly expressed in the presence of the hormone, so that the fold change in the presence of antioestrogens was negative. The expression of several known oestrogen-target genes $(p S 2$, cyclin $D 1$, cathepsin $D$ ) and many novel genes was greater in cells grown in the presence of $17 \beta$-oestradiol. The most pronounced change observed was that for Cyt (Fig. 1a), expression of which in the presence of $17 \beta$-oestradiol was 20 -fold that in the presence of 4-hydroxytamoxifen, 45 -fold that with raloxifen and 70 -fold that with faslodex. Inspection of the 20 probe pairs (Fig. 1a) corresponding to perfectmatch and mismatch oligonucleotides indicated that the majority exhibited similar changes. Under these circumstances, differences in gene expression of as little as $1 \cdot 5$-fold were subsequently confirmed by quantitative RNA analysis (see below).

Expression of potential ER target genes, predicted from the profiling analysis, was then analysed by northern blotting and RNase protection experiments. As an internal control we monitored TPM4 mRNA levels which, as confirmed by the DNA chip analysis, were unaffected by any of the ligands. Expression levels were compared with those in a 


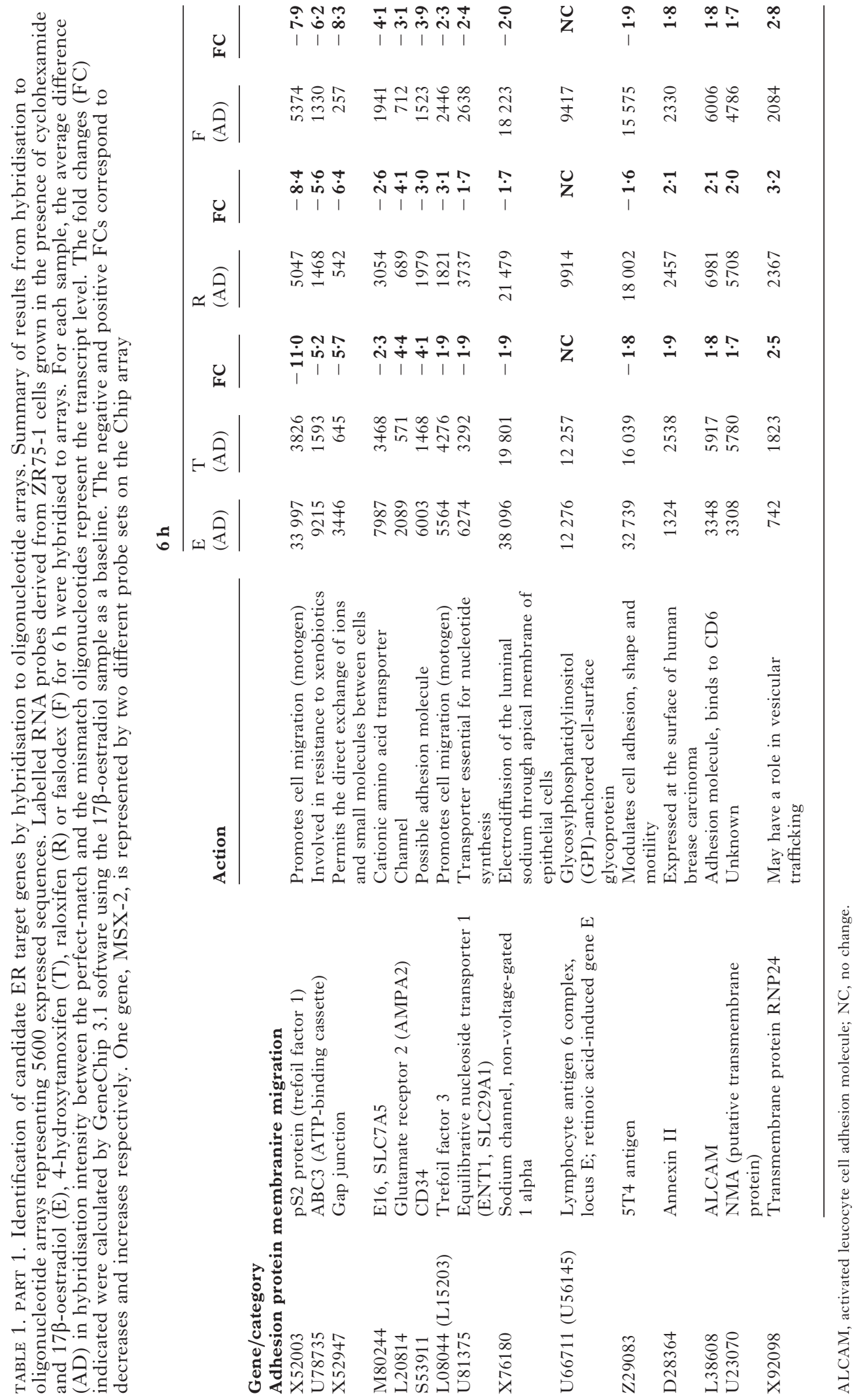




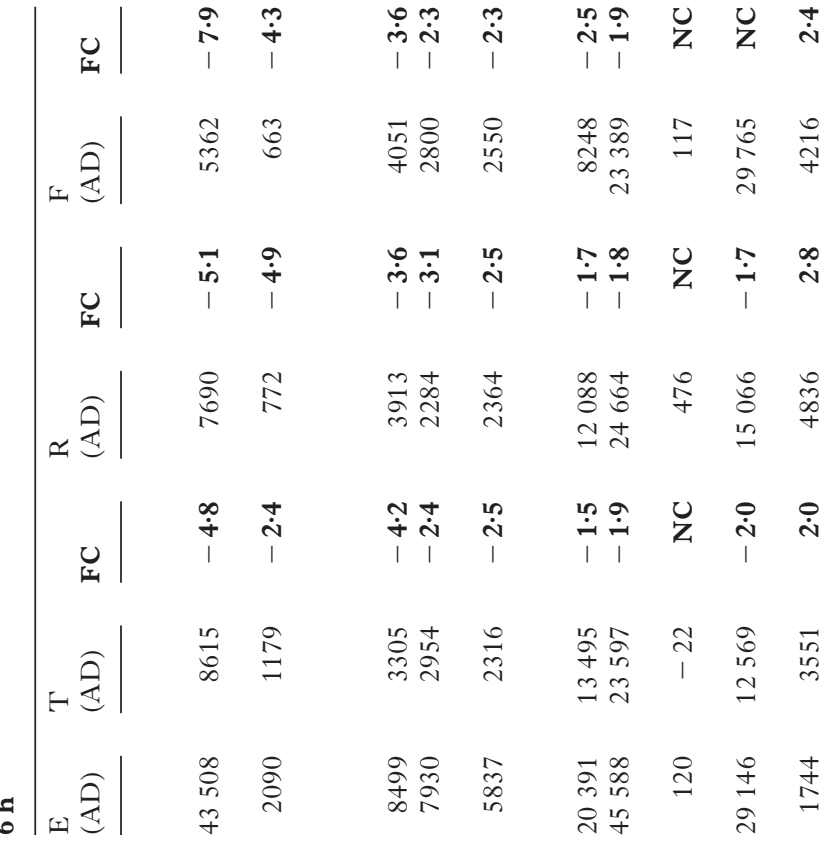
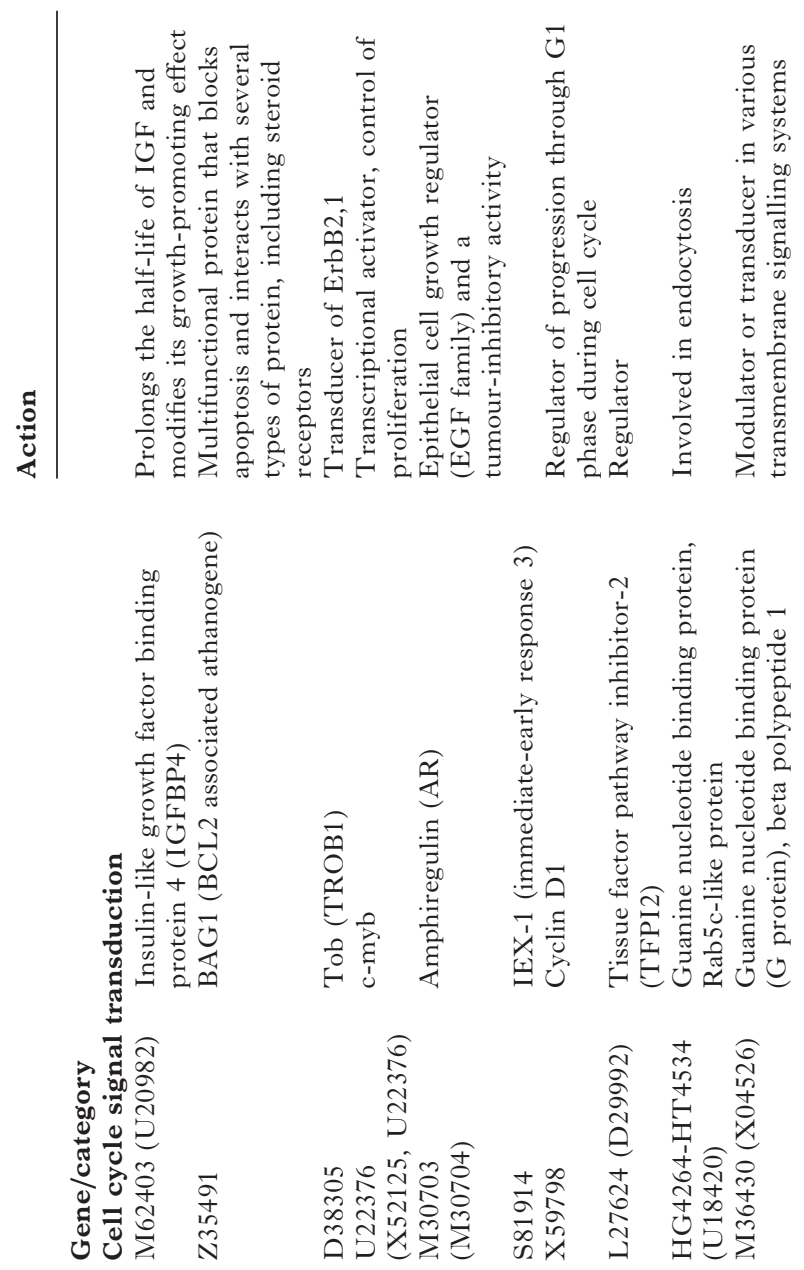


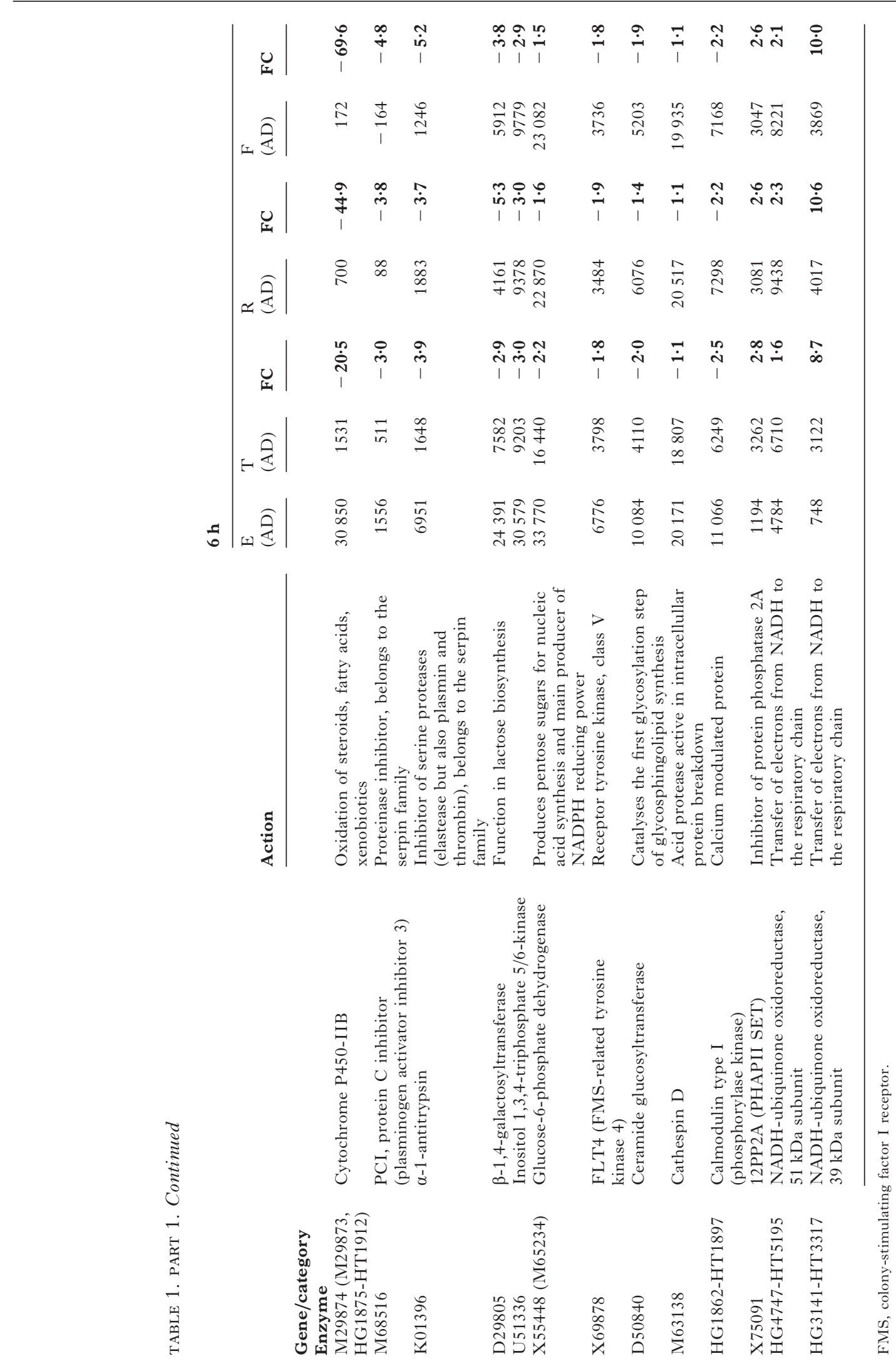




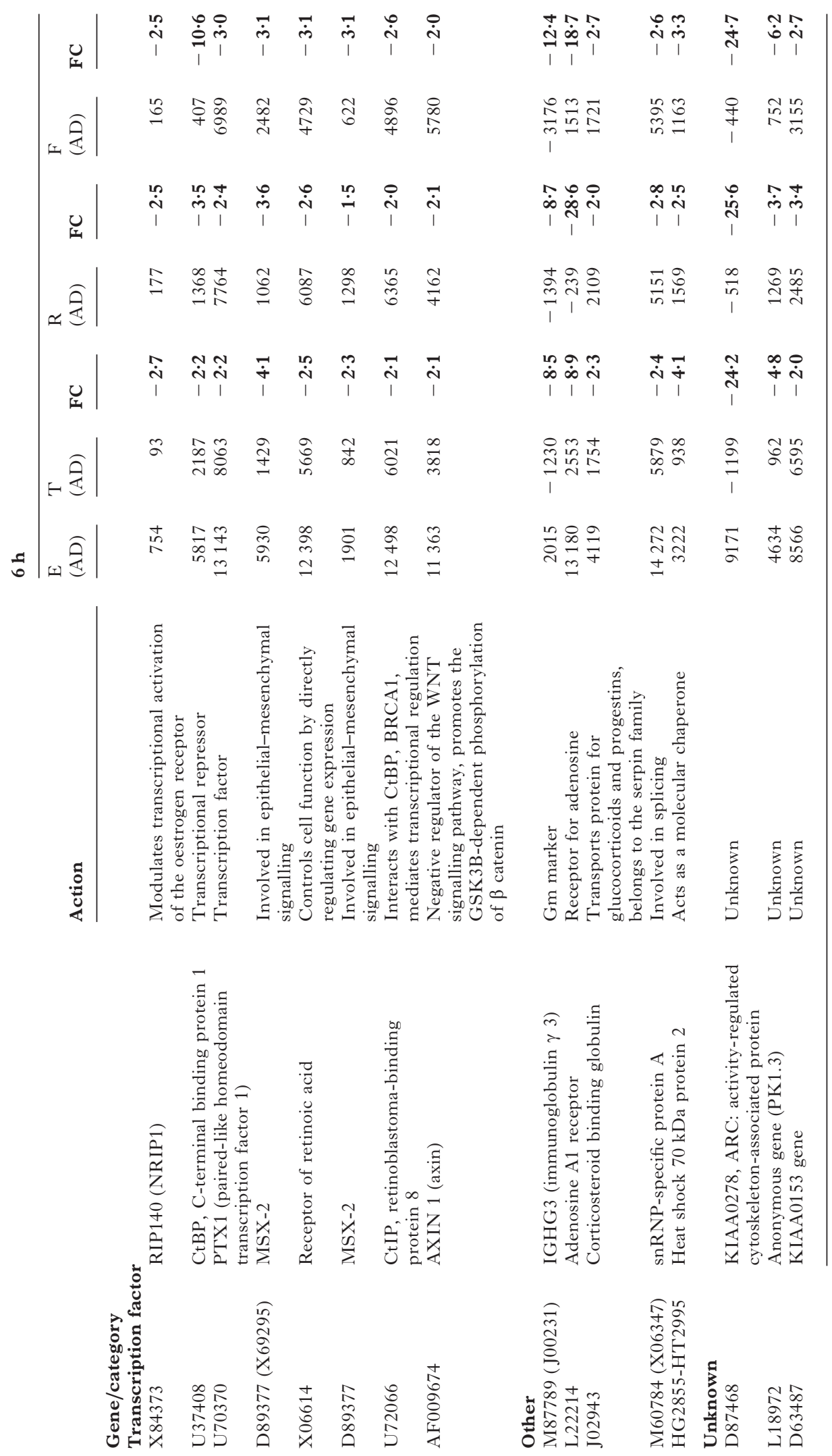




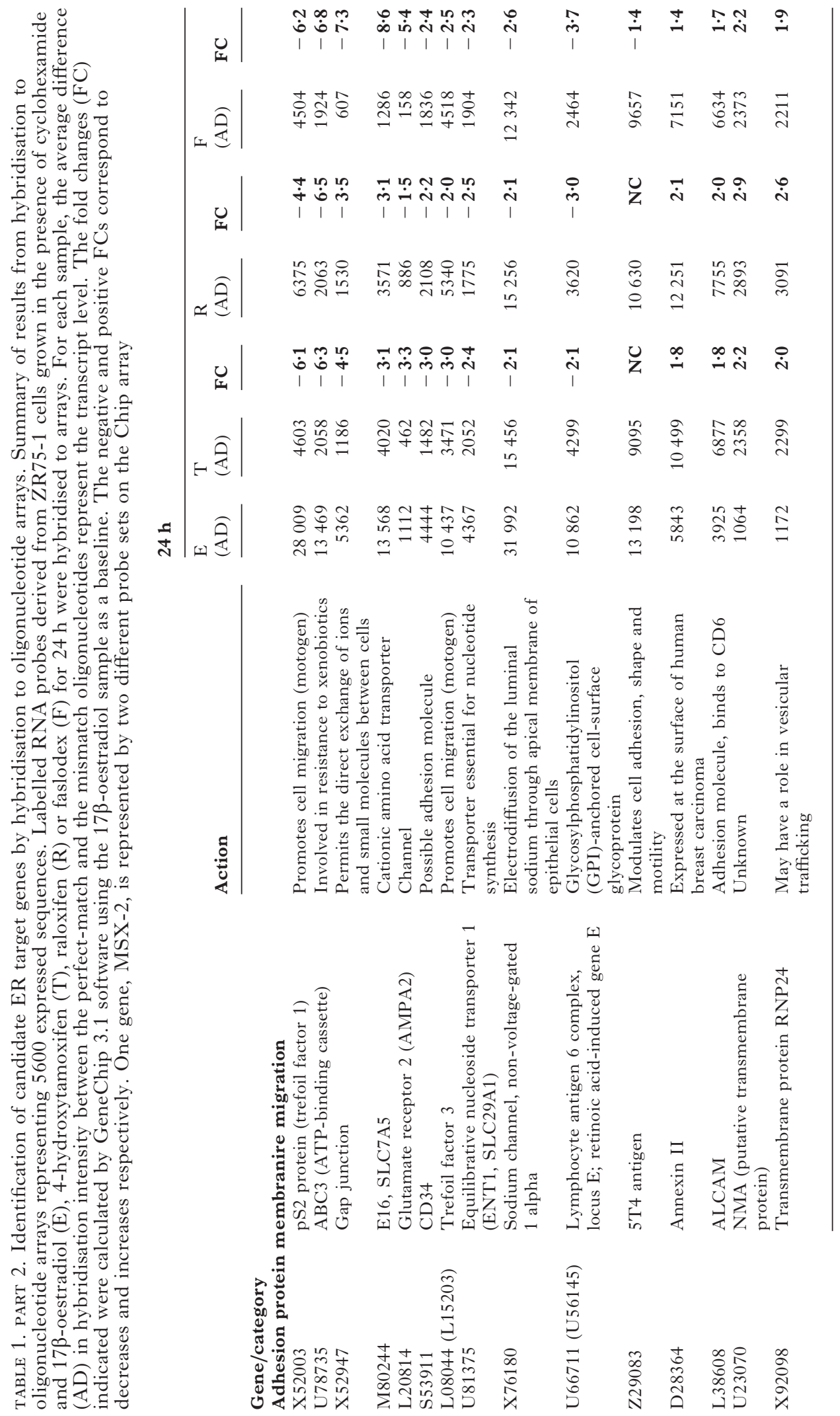




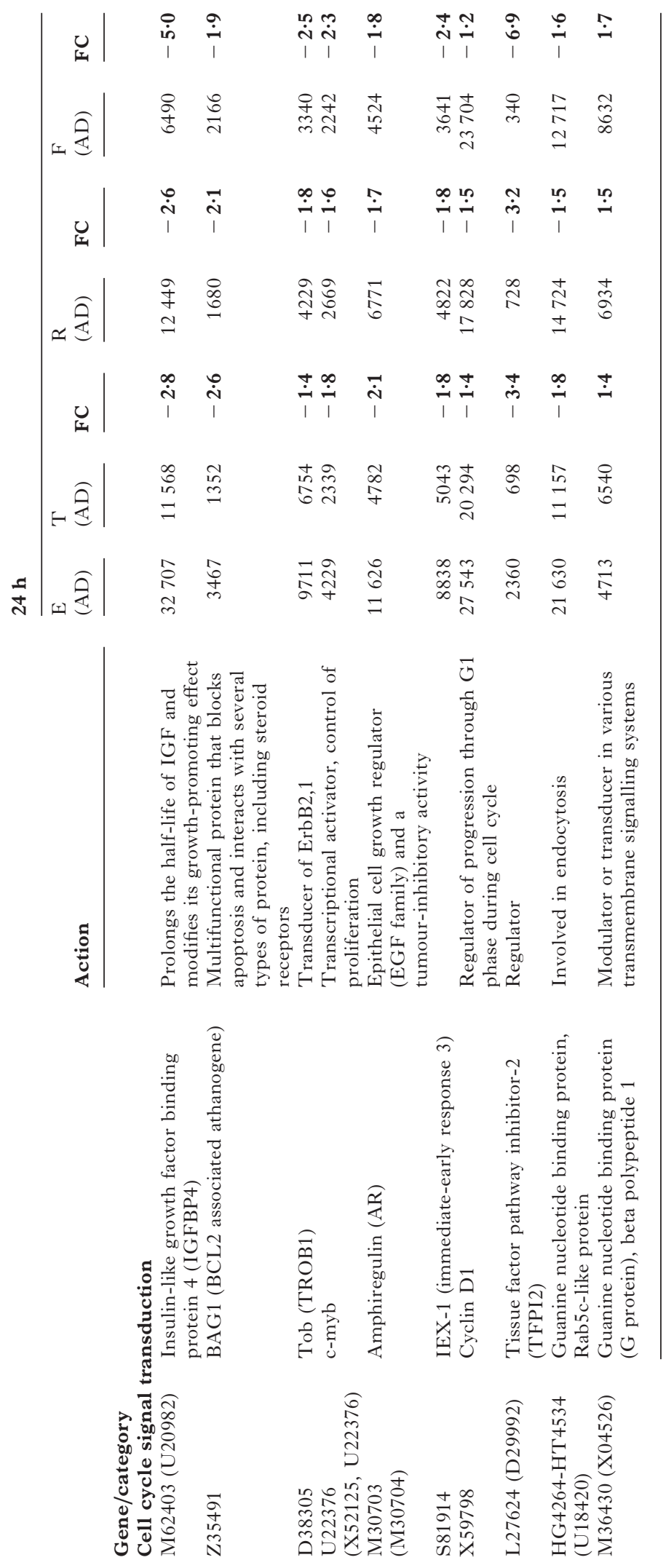




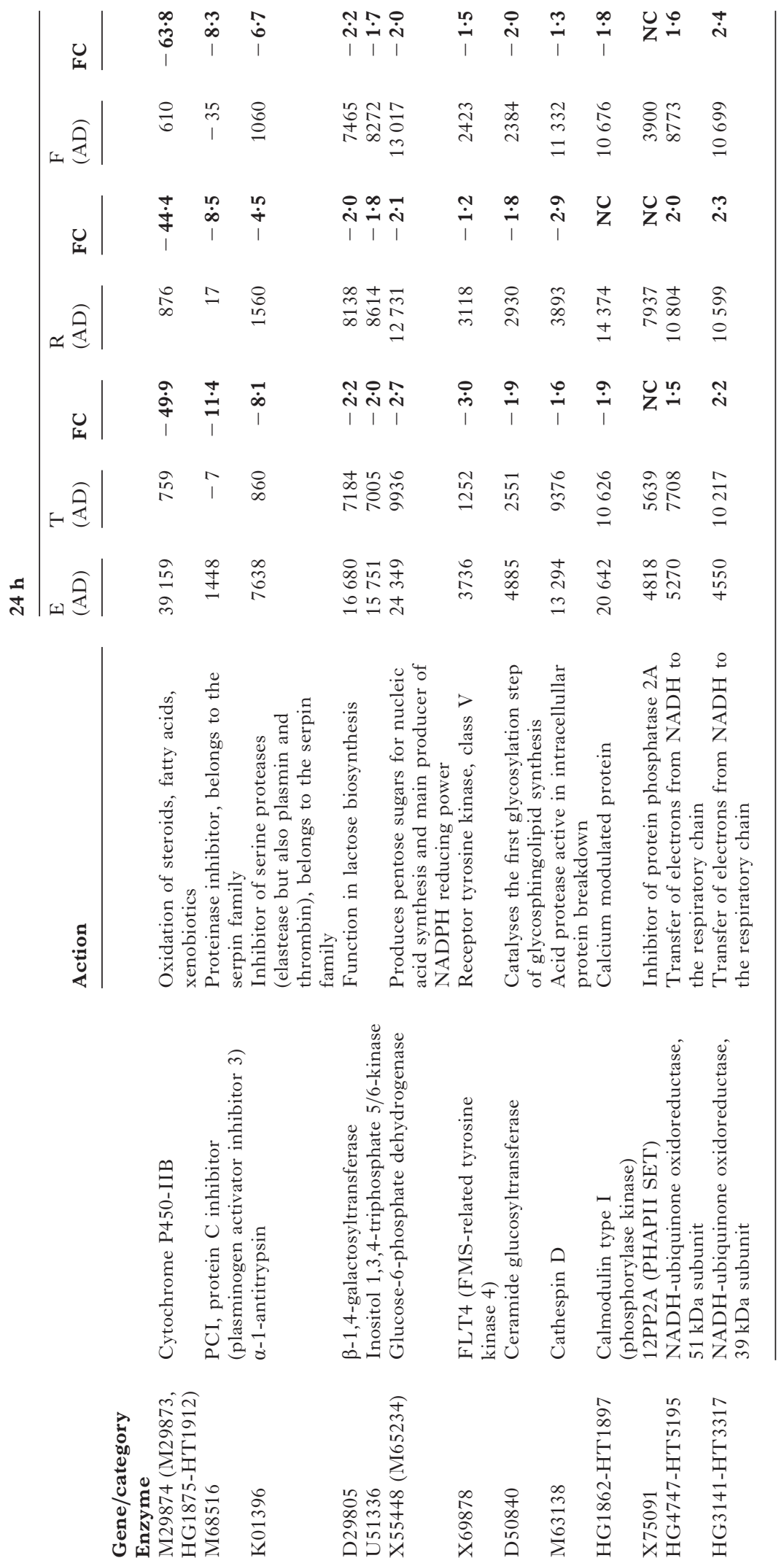




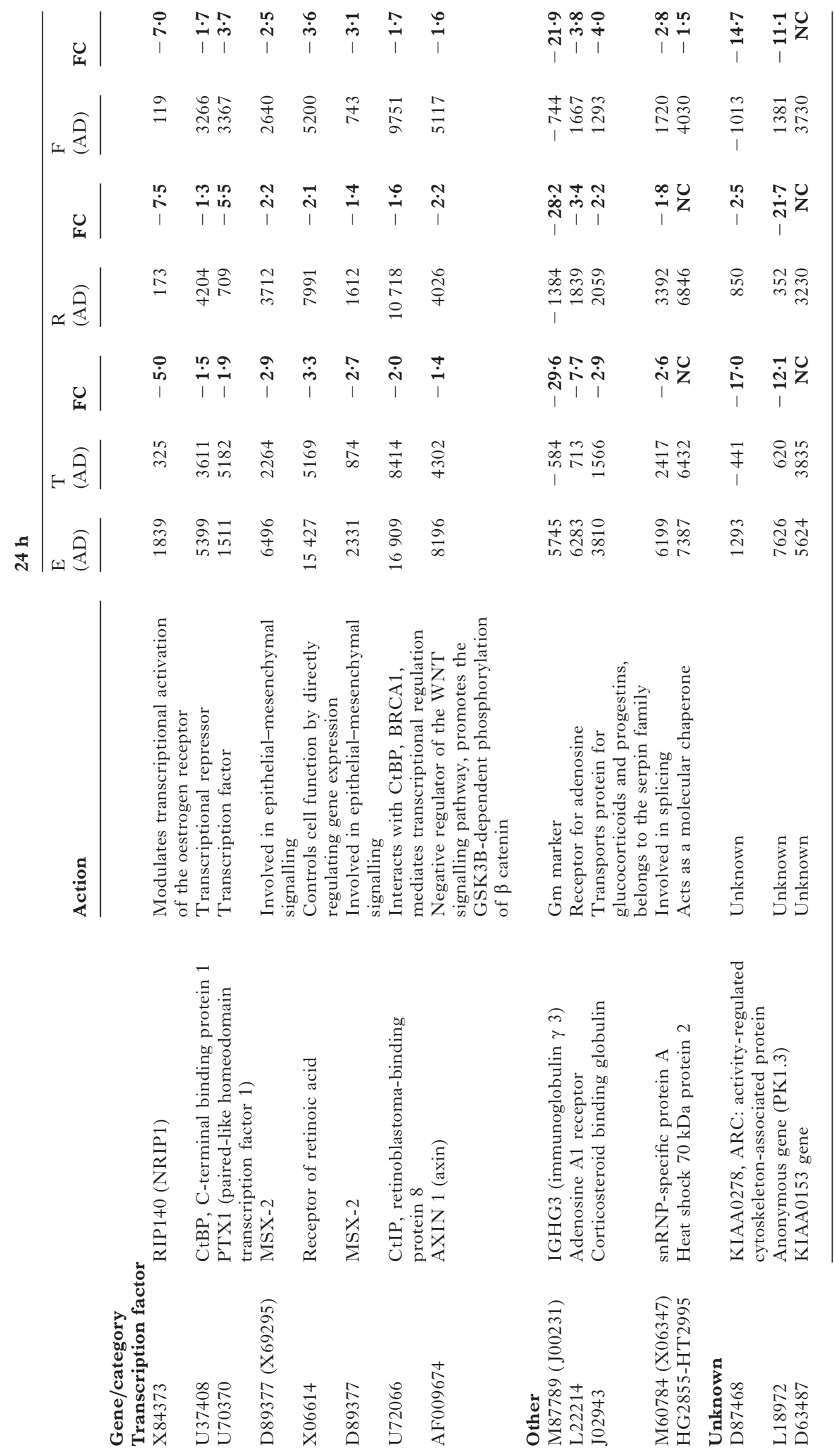




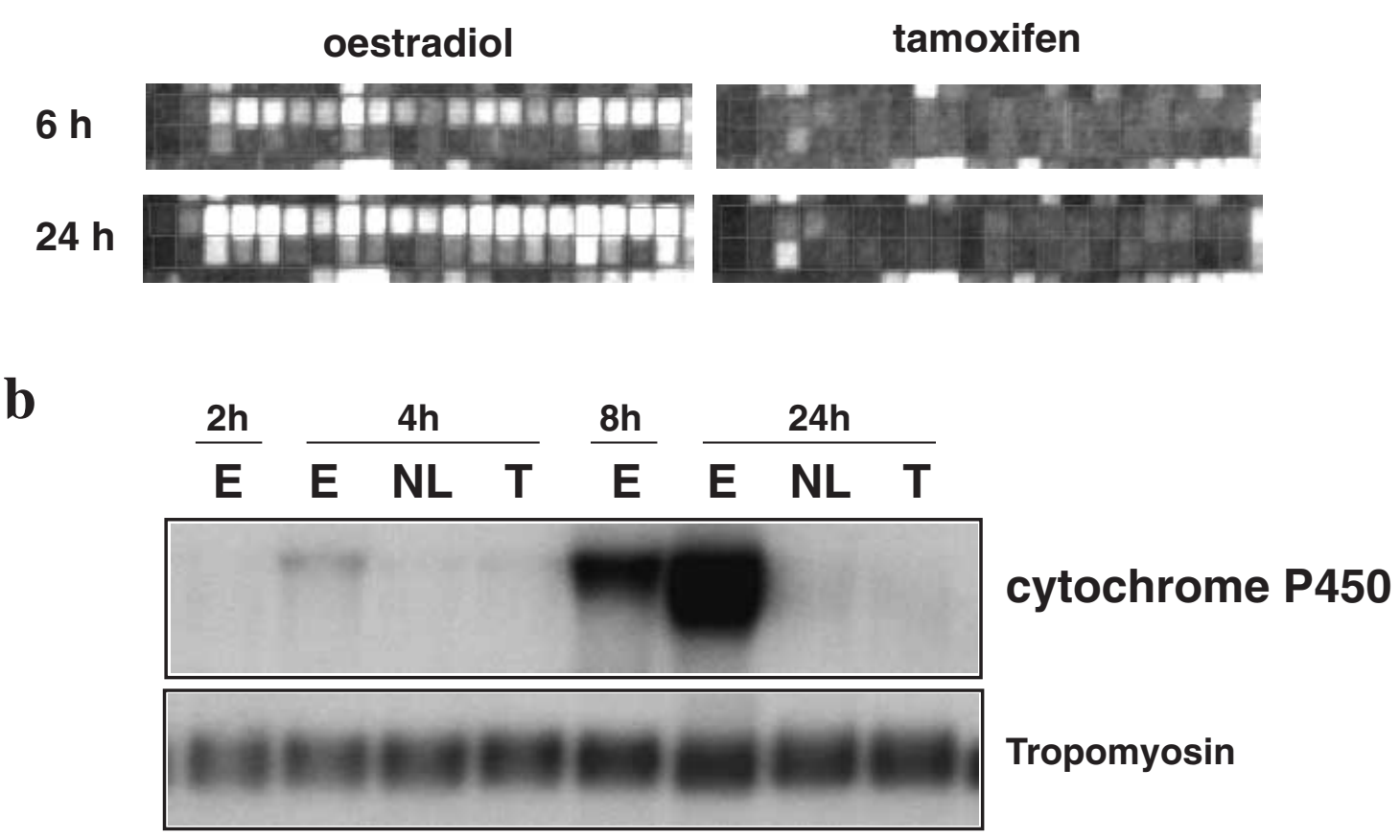

FIGURE 1. Regulation of Cyt (hIIB3) mRNA expression by ER ligands. (a) Transcript monitoring by hybridisation to oligonucleotide arrays. Each gene represented on the array is detected by 20 matched vertical pairs of 25-mer oligonucleotides. The top oligonucleotide in each pair is a perfect-match (PM) 25-mer, and the bottom oligonucleotide has a single base mismatch (MM) at the central position and serves as an internal control for hybridisation specificity. The intensity signals for each oligonucleotide are shown here for the 20 oligonucleotide pairs that detected the gene encoding Cyt. The gene is expressed more in cells cultured in the presence of $17 \beta$-oestradiol than in those cultured with 4-hydroxytamoxifen and its expression increases with time in $17 \beta$-oestradiol-stimulated cells (compare 24 and $6 \mathrm{~h}$ $17 \beta$-oestradiol induction). The average difference in hybridisation intensity between the PM and the MM oligonucleotides is used to determine transcript level. The comparison for each probe pair of the average difference obtained for two samples is used to calculate the fold difference. (b) Time course of Cyt (hIIB3) mRNA induction by oestradiol. Northern blot analysis of $C y t$ (hIIB3) gene expression in ZR75-1 cells treated by different ligands in the presence of cyclohexamide. The cells were cultured in the presence of $17 \beta$-oestradiol (E) or 4-hydroxytamoxifen (T), or in the absence of any ligand (NL). The oligonucleotides spotted on the GeneChip arrays are specific for two different transcripts of the Cyt gene. After RT-PCR and subcloning of cytochrome P450-IIB fragment, we obtained only clones corresponding to the hIIB3 isoform.

control sample from cells grown in the presence of cyclohexamide but in the absence of any ER ligand, to investigate the hormonal regulation of expression of each gene. Consistent with the DNA chip analysis we found that $C y t$ gene expression was markedly stimulated by $17 \beta$-oestradiol relative to that in antioestrogens (Fig. 1b), increasing with time to approximately 100 -fold after $24 \mathrm{~h}$. Surprisingly, we were not able to detect expression of $C y t$ in the human MCF-7 breast cancer cell line (data not shown).

We then analysed expression of a number of additional genes in ZR75-1 cells predicted to be differentially expressed in the presence of different ER ligands according to the HuGeneFL chip analysis, as shown in Figures2 and 3a. Thus $17 \beta$-oestradiol increased the expression of the cationic amino acid transporter E16 by approximately fivefold after $6 \mathrm{~h}$ and 10-fold over a $24 \mathrm{~h}$ period, whereas tamoxifen and raloxifen, but not faslodex, increased expression up to twofold during this period. Levels of mRNA for Gap were markedly increased by $17 \beta$-oestradiol (10- to 15 -fold), but were completely unaffected by antagonist. 17 $\beta$-Oestradiol also increased the expression of $G 6 P D$ and $I P 3 K$, both increasing by up to 


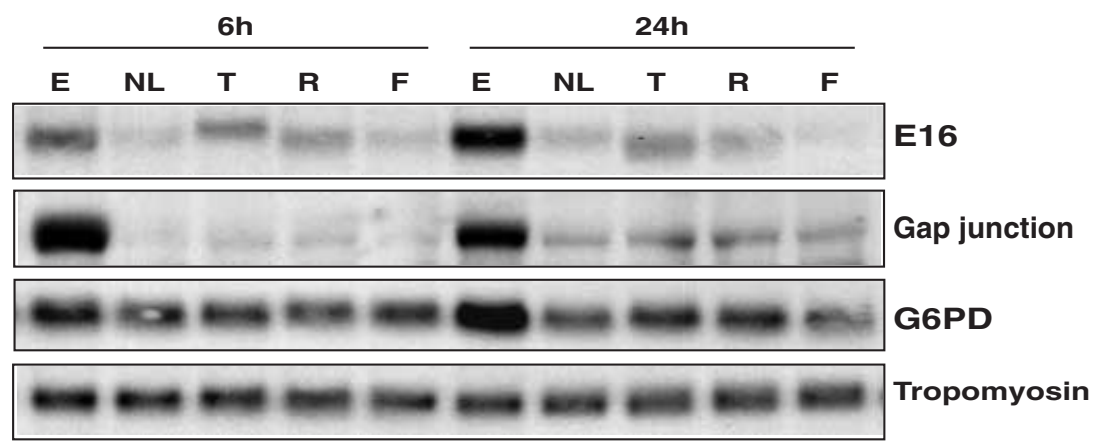

FIGURE 2. Northern blot analysis of E16, Gap (alpha 1) and G6PD mRNA expression in ZR75-1 treated by different ER ligands in the presence of cyclohexamide. The cells were cultured for 6 or $24 \mathrm{~h}$ in the presence of $17 \beta$-oestradiol (E), 4-hydroxytamoxifen $(\mathrm{T})$, raloxifen $(\mathrm{R})$ or faslodex $(\mathrm{F})$, or in the absence of any ligand (NL). The Gap transcript is 3038 bases long; another transcript corresponding to connexin 43 was detected with the same probe, but its expression level was constant (data not shown).

fivefold but with different kinetics. We next examined the regulation of a number of genes in both ZR75-1 and MCF7 cells (Fig. 3b). IGFBP4 gene was stimulated rapidly and markedly by 10 to 15 -fold in both cell lines and the $I E X-1$ gene was also regulated similarly in both cell lines, although the absolute levels of expression differed signifi- cantly. Finally, we examined the expression of the nuclear receptor cofactor $R I P 140$ and $T o b$ by RNase mapping and found that they were also increased by up to threefold in the presence of $17 \beta$-oestradiol (Fig. 4). Although these genes are all oestrogen target genes, their expression was regulated with different kinetics. Increases in

a

\begin{tabular}{|c|c|c|c|c|c|c|c|c|c|c|}
\hline \multicolumn{5}{|c|}{$6 h$} & \multicolumn{5}{|c|}{$24 h$} & \\
\hline $\mathbf{E}$ & NL & $\mathbf{T}$ & $\mathbf{R}$ & $\mathbf{F}$ & E & NL & $\mathbf{T}$ & $\mathbf{R}$ & $\mathbf{F}$ & \\
\hline & $\mathrm{m}$ & 10 & 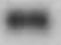 & 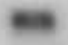 & $=$ & nas & 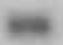 & $=$ & $\mathrm{m}$ & IP3 kinase \\
\hline
\end{tabular}

b

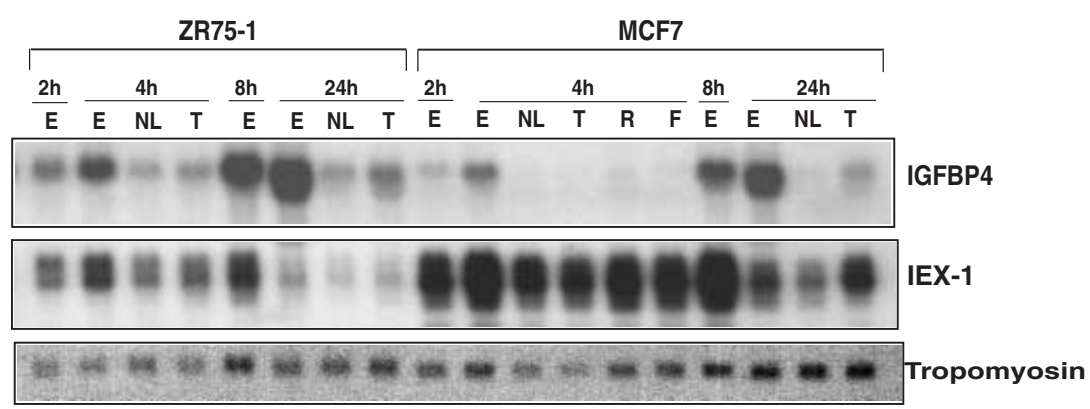

FIGURE 3. Northern blot analysis of (a) IP3K expression in ZR75-1 cells and (b) IGFBP4 and IEX-1 expression in ZR75-1 and MCF7 cells treated by different ER ligands in the presence of cyclohexamide. The cells were cultured for defined periods (as specified) in presence of $17 \beta$-oestradiol (E), 4-hydroxytamoxifen $(\mathrm{T})$, raloxifen $(\mathrm{R})$ or faslodex $(\mathrm{F})$, or in the absence of any ligand (NL). 
a

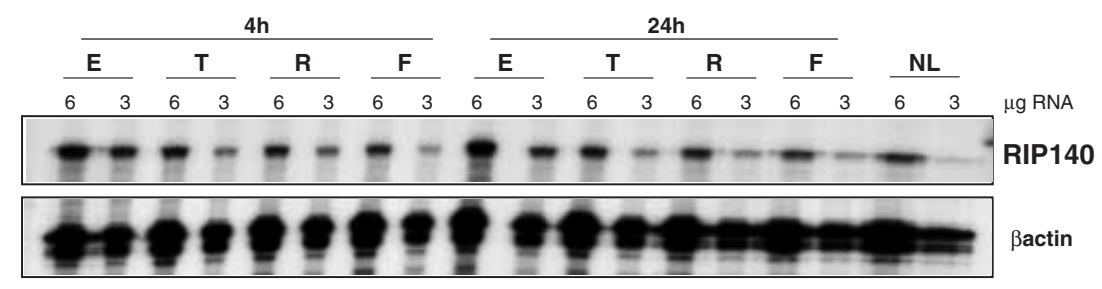

b

\begin{tabular}{|c|c|c|c|c|c|c|c|c|c|c|c|c|c|c|c|c|c|}
\hline \multicolumn{7}{|c|}{$4 \mathrm{~h}$} & \multicolumn{8}{|c|}{$24 \mathrm{~h}$} & \multirow{2}{*}{\multicolumn{2}{|c|}{$\mathrm{NL}$}} & \multirow[b]{3}{*}{$\mu \mathrm{g}$ RNA } \\
\hline & & & $\mathbf{R}$ & & & $\mathbf{F}$ & & $E$ & & $T$ & & 8 & & $F$ & & & \\
\hline 1.5 & 3 & 1.5 & 3 & 1.5 & 3 & 1.5 & 3 & 1.5 & 3 & 1.5 & 3 & 1.5 & 3 & 1.5 & 3 & 1.5 & \\
\hline 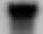 & & $=$ & $=$ & $=$ & $=$ & $=$ & $=$ & $=$ & - & $\mathbf{n}$ & & $=$ & & - & & $=$ & Tob \\
\hline
\end{tabular}

c

\begin{tabular}{|c|c|c|c|c|c|c|c|c|c|}
\hline $2 h$ & & & $4 \mathrm{~h}$ & & & $8 \mathrm{~h}$ & \multirow{2}{*}{\multicolumn{3}{|c|}{$24 \mathrm{~h}$}} \\
\hline$E$ & $\mathrm{NL}$ & $E$ & $\mathbf{T}$ & $\mathbf{R}$ & $\mathbf{F}$ & $E$ & & & \\
\hline- & $=$ & $\sigma$ & $=$ & $=$ & $=$ & 0 & $=$ & $=$ & - \\
\hline- & - & - & - & $=$ & - & $z$ & $=$ & - & $=$ \\
\hline
\end{tabular}

FIGURE 4. Regulation of RIP140 and Tob mRNA expression by ER ligands. (a) RNase protection analysis of RIP140 in ZR75-1 cells. (b) Tob expression in ZR75-1 cells. (c) Tob expression in MCF7 cells. Cells were cultured for 4 or $24 \mathrm{~h}$ in the presence of $17 \beta$-oestradiol (E), 4-hydroxytamoxifen (T), raloxifen $(\mathrm{R})$ or faslodex $(\mathrm{F})$, or in the absence of any ligand (NL). RNase protection experiments were carried out using different amounts of total RNA to determine accurate quantification and calculation of fold inductions. The results shown for MCF7 were obtained with $1.5 \mu \mathrm{g}$ total RNA; those results are consistent with the results obtained with $3 \mu \mathrm{g}$.

mRNAs for G6PD, IP3K, Gap, IEX-1 and Tob were apparent within $6 \mathrm{~h}$ and there was no further increase after $24 \mathrm{~h}$. In contrast, although E16 and IGFBP4 mRNAs were increased within $6 \mathrm{~h}$, they were substantially greater after $24 \mathrm{~h}$, whereas the increases in IEX-1 and Tob mRNA were transient. The majority of these genes were unaffected by antioestrogen treatment, with the exception of E16 and IGFBP4, which increased about twofold in the presence of 4-hydroxytamoxifen and raloxifen.

\section{DISCUSSION}

The characterisation of gene expression profiles for tumour cell lines provides a framework for assessing the biological significance of expression patterns in a specific tumour (Perou et al. 1999, 2000, Ross et al.
2000). We focused on target genes for $17 \beta$ oestradiol in view of its importance as a mitogen in a subset of ER-positive cell lines and tumours. In this study we identified a number of oestrogen-regulated genes, all of which were direct targets, as they were differentially expressed in the presence of cyclohexamide. We have organised the genes into clusters according to their function.

Several genes are implicated in cell proliferation. Thus Tob, which was first identified by its ability to interact with ErbB-2, may have antiproliferative activity (Matsuda et al. 1996, Yoshida et al. 1997). IGFBP4 has been proposed to modulate binding of IGFs to their receptors and thereby regulate IGF action. Interestingly, IGFBP4 induction by $17 \beta$ oestradiol has recently been described by other groups (Glantschnig et al. 1998, Zazzi et al. 1998). Given that IGFBP4 has been found to inhibit the 
growth of breast cancer cells driven by IGF pathways (Corcoran et al. 1996), it is conceivable that IGFBP4 expression alters the sensitivity of breast cancers to the mitogenic effects of oestrogens. IEX-1, which is an immediate early response gene induced by serum growth factor, is a member of the nuclear factor $-\kappa \mathrm{B} / \mathrm{Rel}(\mathrm{NF}-\kappa \mathrm{B})$ family of transcription factors and may be important in cell survival (Wu et al. 1998). Finally, the identification of cyclin D1 was expected, as it clearly has an important role in cell cycle progression in response to mitogens, including oestrogens (Planas-Silva \& Weinberg 1997, Prall et al. 1997).

A number of differentially expressed genes encode membrane-associated proteins or proteins involved in adhesion, migration or communication between cells. For example, Gap alpha 1, a member of the connexin gene family, is a component of gap junctions that are important in cellular differentiation and organogenesis, and loss of its function is correlated with progression to a malignant phenotype (Locke 1998). The observation that its expression is upregulated by oestrogens in ZR75-1 cells is consistent with the relatively well differentiated phenotype of this ER-positive breast cancer cell line.

A third group consists of genes that encode enzymes involved in cell metabolism. The G6PD gene encodes a cytosolic enzyme the main function of which is to produce NADPH, a key electron donor in the defence against oxidising agents and in reductive biosynthetic reactions. Interestingly, a positive effect of $17 \beta$-oestradiol on G6PD activity in MCF7 cells has previously been described (Monet et al. 1987, Thomas et al. 1990). The Cyt family of enzymes are involved in steroid metabolism and in the metabolism of various xenobiotics (Nelson et al. 1993, Honkakoski \& Negishi 2000). These enymes are highly expressed in the liver, where they have been shown to be induced by a number of xenobiotics acting through nuclear receptors such as constitutively acting receptor, pregnane $\mathrm{X}$ receptor and peroxisome proliferator activating receptor alpha. It is difficult to judge whether the expression of this enzyme in breast cancer cells may affect their senstivity to xenobiotics, and the importance of environmental oestrogens as a risk factor for breast cancer remains rather speculative.

The relevance of the majority of oestrogen target genes to oestrogen-dependent growth is unclear, but further analysis may provide new markers for the analysis of hormone responses in specific tumours. Thus it would be informative to examine them in a large number of ER-positive tumour samples to determine if their expression correlates with their response to endocrine therapy.

\section{ACKNOWLEDGEMENTS}

We wish to thank Affymetrix for the opportunity to use the GeneChip technology and for supplying the microarrays within the Academic User Center Program (this research was supported, in part, by an NIH Grant (PO1HG01323) to the Affymetrix User Center Program), and especially Gene Tanimoto (Affymetrix, Santa Clara) for his continuous help with the microarray experiments and data analysis. We are grateful to Alan Wakeling and Maurice Needham (AstraZeneca Pharmaceuticals, Macclesfield, UK) for providing the antioestrogens used in this study. We also thanks John Sgouros in the Computational Genome Analysis lab (ICRF) for help with data analysis and bioinformatics, and Roger White, Mark Uden and Clive Dickson for suggestions and comments on the manuscript.

\section{REFERENCES}

Bertucci F, Houlgatte R, Benziane A, Granjeaud S, Adelaide J, Tagett R, Loriod B, Jacquemier J, Viens P, Jordan B, Birnbaum D \& Nguyen C 2000 Gene expression profiling of primary breast carcinomas using arrays of candidate genes. Human Molecular Genetics 9 2981-2991.

Brown AM, Jeltsch JM, Roberts M \& Chambon P 1984 Activation of pS2 gene transcription is a primary response to estrogen in the human breast cancer cell line MCF-7. PNAS 81 6344-6348.

Chalbos D, Philips A, Galtier F \& Rochefort H 1993 Synthetic antiestrogens modulate induction of $\mathrm{pS} 2$ and cathepsin D messenger ribonucleic acid by growth factors and adenosine 3', 5'-monophosphate in MCF-7 cells. Endocrinology 133 571-576.

Corcoran D, Perachiotti A \& Darbre PD 1996 Increased autocrine production of insulin-like growth factor II (IGF-II) alters serum sensitivity of MCF-7 human breast cancer cell proliferation. Cell Proliferation 29 479-493.

Dhingra K 1999 Antiestrogens - tamoxifen, SERMs and beyond. Investigation in New Drugs 17 285-311.

Glantschnig H, Varga F, Luegmayr E \& Klaushofer K 1998 Characterization of the mouse insulin-like growth factor binding protein 4 gene regulatory region and expression studies. DNA Cell Biology 17 51-60.

Honkakoski P \& Negishi M 2000 Regulation of cytochrome P450 (CYP) genes by nuclear receptors. Biochemical fournal 347 321-337.

Howell A, Osborne CK, Morris C \& Wakeling AC 2000 ICI 182,780 (faslodex): development of a novel, 'pure' antiestrogen. Cancer 89 817-825.

Jordon VC \& Morrow M 2000 Tamoxifen, raloxifen, and the prevention of breast cancer. Endocrine Reviews 20 253-278.

Levenson AS \& Jordan VC 1999 Selective oestrogen receptor modulation: molecular pharmacology for the millennium. European Fournal of Cancer 35 1628-1639.

Locke D 1998 Gap junctions in normal and neoplastic mammary gland. Fournal of Pathology 186 343-349.

Masiakowski P, Breathnach R, Bloch J, Gannon F, Krust A \& Chambon P 1982 Cloning of cDNA sequences of hormoneregulated genes from the MCF-7 human breast cancer cell line. Nucleic Acids Research 10 7895-7903. 
Matsuda S, Kawamura-Tsuzuku J, Ohsugi M, Yoshida M, Emi M, Nakamura Y, Onda M, Yoshida Y, Nishiyama A \& Yamamoto T 1996 Tob, a novel protein that interacts with p185 erbB2, is associated with anti-proliferative activity. Oncogene 12 705-713.

Monet J, Thomas M, Dautigny N, Brami M \& Bader C 1987 Effects of 17 beta-estradiol and R5020 on glucose-6phosphate dehydrogenase activity in MCF-7 human breast cancer cells: a cytochemical assay. Cancer Research 47 $5116-5119$.

Montano MM \& Katzenellenbogen BS 1997 The quinone reductase gene: a unique estrogen receptor-regulated gene that is activated by antiestrogens. PNAS 94 2581-2586.

Nacht M, Ferguson AT, Zhang W, Petroziello JM, Cook BP, Gao YH, Maguire S, Riley D, Coppola G, Landes GM, Madden SL \& Sukumar S 1999 Combining serial analysis of gene expression and array technologies to identify genes differentially expressed in breast cancer. Cancer Research 59 5464-5470.

Nelson DR, Kamataki T, Waxman DJ, Guengerich FP, Estabrook RW, Feyereisen R, Gonzalez FJ, Coon MJ, Gunsalus IC, Gotoh O, Okuda K \& Nebert DW 1993 The P450 superfamily: update on new sequences, gene mapping, accession numbers, early trivial names of enzymes, and nomenclature. DNA Cell Biology 12 1-51.

Paech K, Webb P, Kuiper GG, Nilsson S, Gustafsson JA, Kushner PJ \& Scanlan TS 1997 Differential ligand activation of estrogen receptors ER $\alpha$ and ER $\beta$ at AP1 sites. Science 277 1508-1510.

Perou CM, Jeffrey SS, van de Rijn M, Rees CA, Eisen MB, Ross DT, Pergamenschikov A, Williams CF, Zhu SX, Lee JC, Lashkari D, Shalon D, Brown PO \& Botstein D 1999 Distinctive gene expression patterns in human mammary epithelial cells and breast cancers. PNAS 96 9212-9217.

Perou CM, Sorlie T, Eisen MB, van de Rijn M, Jeffrey SS, Rees CA, Pollack JR, Ross DT, Johnsen H, Akslen LA, Fluge O, Pergamenschikov A, Williams C, Zhu SX, Lonning PE, Borresen-Dale AL, Brown PO \& Botstein D 2000 Molecular portraits of human breast tumours. Nature 406 $747-752$.

Planas-Silva MD \& Weinberg RA 1997 Estrogen-dependent cyclin E-cdk2 activation through p21 redistribution. Molecular and Cellular Biology 17 4059-4069.
Prall O, Sarcevic B, Musgrove E, Watts C \& Sutherland R 1997 Estrogen-induced activation of Cdk4 and Cdk2 during G1-S phase progression is accompanied by increased cyclin D1 expression and decreased cyclin-dependent kinase inhibitor association with cyclin E-Cdk2. Fournal of Biological Chemistry 272 10882-10894.

Ross DT, Scherf U, Eisen MB, Perou CM, Rees C, Spellman P, Iyer V, Jeffrey SS, Van de Rijn M, Waltham M, Pergamenschikov A, Lee JC, Lashkari D, Shalon D, Myers TG, Weinstein JN, Botstein D \& Brown PO 2000 Systematic variation in gene expression patterns in human cancer cell lines. Nature Genetics 24 227-235.

Rozen S \& Skaletsky H 2000 Primer 3 on the WWW for general users and for biologist programmers. Methods in Molecular Biology 132 365-386.

Sgroi DC, Teng S, Robinson G, LeVangie R, Hudson JR \& Elkahloun AG 1999 In vivo gene expression profile analysis of human breast cancer progression. Cancer Research $\mathbf{5 9}$ 5656-5661.

Thomas M, Bader C \& Monet J 1990 Sex steroid hormone modulation of NADPH pathways in MCF-7 cells. Cancer Research 50 1195-1200.

Wakeling AE \& Bowler J 1988 Biology and mode of action of pure antioestrogens. Fournal of Steroid Biochemistry 30 141-148.

Westley BR \& May FE 1987 Oestrogen regulates cathepsin D mRNA levels in oestrogen responsive human breast cancer cells. Nucleic Acids Research 15 3773-3786.

Wu MX, Ao Z, Prasad KV, Wu R \& Schlossman SF 1998 IEX-1L, an apoptosis inhibitor involved in NF-kappaBmediated cell survival. Science 281 998-1001.

Yoshida Y, Matsuda S \& Yamamoto T 1997 Cloning and characterization of the mouse tob gene. Gene 191 109-113.

Zazzi H, Nikoshkov A, Hall K \& Luthman H 1998 Structure and transcription regulation of the human insulin-like growth factor binding protein 4 gene (IGFBP4). Genomics 49 401-410.

RECEIVED IN FINAL FORM 2 August 2001 ACCEPTED 7 August 2001 